\title{
A NECESSIDADE DE CRIAÇÃO DE UM ORGANISMO INTERNACIONAL DE RESOLUÇÃo DE CONFLITOS EM MATÉRIA AMBIENTAL DIANTE DA RECONSTRUÇÃO DA SOBERANIA ESTATAL
}

The need for stablishment of international organization of conflict resolution in environmental toward the reconstruction

of state sovereignty

\section{Camila Martins De Oliveira}

Advogada, professora da Polícia Militar de Minas Gerais e da Escola Superior Dom Helder wCâmara. Mestranda em Direito Ambiental e Desenvolvimento Sustentável pela Escola Superior Dom Helder Câmara. E-mail: oliveira_camilam@yahoo.com.br

\section{Dione Ferreira Santos}

Procuradora do Município de Belo Horizonte. Mestranda em Direito Ambiental e Desenvolvimento Sustentável pela Escola Superior Dom Helder Câmara.

E-mail: dione@pbh.gov.br

RECEBIDO EM: 26.08.12

Aprovado EM: 24.11.12

\section{RESUMo}

O presente artigo tem como objetivo demonstrar a necessidade de uma governança ambiental a nível global vislumbrada a partir da substituição ou fortalecimento do atual e, pouco eficaz, Programa das Nações Unidas para o Meio Ambiente (PNUMA) por uma organização internacional capaz de vincular os Estados no cumprimento das obrigações ambientais assumidas, nos moldes da Organização Mundial do Comércio (OMC). Procura-se estabelecer um parâmetro de ingerência ambiental através da reconstrução do conceito de soberania estatal baseado na internacionalização do direito ambiental, bem como no respeito aos princípios da solidariedade e do patrimônio comum da humanidade. 
Palavras-chave: Soberania nacional. Responsabilidade ambiental INTERNACIONAL. PRINCÍPIO DO PATRIMÔNIO COMUM DA HUMANIDADE. SOBERANIA COMPARTILHADA. ORGANIZAÇÕES INTERNACIONAIS.

\section{Abstract:}

This article aims to demonstrate the need for a global environmental governance envisoned from the replacement or strenghthenig of the current and ineffective United Nations Environment Programme (UNEP) by na international organization capable of binding states in the fulfillment of enironmental commitments along the lines of the World Trade Organization (WTO). We seek to stablish a measure of interference by environmental reconstruction of the concept of state sovereignty based on the internationalization of environmental Law, and respect the principle of solidarity and the principle of common heritage of humanity.

KeYWORDS: StATE SOVEREIGNTY. INTERNATIONAL ENVIRONMENTAL Responsibility. Principle of COMmon heritage of humanity. Shared SOVEREIGNTY. INTERNATIONAL ORGANIZATIONS.

\footnotetext{
SuMÁRIo: Introdução. 1. Organizações internacionais de resolução de conflitos: responsabilidade internacional. 1.1. A internacionalização do Direito Ambiental: PNUMA e OMMA. 2. Soberania nacional: ingerência internacional no território nacional. 2.1. A reconstrução da soberania nacional. 3. O princípio do patrimônio comum da humanidade. Conclusão. Referências.
}

\section{INTRODUÇÃo}

O Direito Internacional Ambiental deve servir como instrumento capaz de regular as relações estabelecidas entre os Estados, sem se esquecer de que seu principal objetivo é a promoção do direito fundamental ao meio ambiente ecologicamente equilibrado.

Neste sentido, os Estados ao se comprometerem no plano internacional em matérias ambientais, vinculam-se às normas estabelecidas neste contexto. De tal sorte que a não observância de tais normas internacionais no plano interno dos Estados enseja a não efetividade do Direito Internacional Ambiental na proteção do meio ambiente. 
Diante da excessiva quantidade de acordos internacionais ineficazes no campo ambiental como o Protocolo de Kioto, surge a necessidade de criação de um organismo internacional que seja responsável por vincular os Estados no cumprimento das metas estabelecidos nos supracitados documentos, uma vez que o Programa das Nações Unidas para o Meio Ambiente (PNUMA) não está obtendo êxito em desempenhar tal papel.

No entanto, a ingerência internacional em matéria ambiental não é um tema fácil de ser discutido muito menos de ser implementado haja vista a existência de discussões calorosas acerca de quais seriam os limites de intervenção, baseada na vinculação anteriormente citada, e, se restaria preservada o instituto da soberania estatal.

Traçado o contexto da atual situação ambiental internacional, ou seja, diante da não atuação do PNUMA na resolução de conflitos de ordem ambiental, a proposta do presente artigo consiste em demonstrar como o surgimento de uma organização internacional ambiental vinculativa, derivada da internacionalização das matérias ecológicas, tornou-se imprescindível à proteção do meio ambiente ao mesmo tempo em que interfere diretamente no moderno significado de soberania estatal no cenário da sociedade de risco.

\section{Organizações internacionais de Resolução de Conflitos: RESPONSABILIDADE INTERNACIONAL}

Desde o período pós-guerra e, principalmente, a partir das atrocidades cometidas contra seres humanos na Segunda Guerra Mundial - como exterminação em massa - o cenário internacional modificou o comportamento estabelecido entre as nações soberanas e os organismos internacionais.

Surge a partir de 1948, com a Declaração Universal de Direitos do Homem, o estabelecimento de um novo cenário global, no qual os Estados, até então completamente soberanos em suas decisões, passam a vincular-se a documentos jurídicos em âmbito supranacional.

Na visão de Habermas há um "enfraquecimento do Estado nacional"286, uma vez que cresce a necessidade de controle externo sobre organismos internos.

O filósofo segue sua exposição:

Com base na construção de blocos militares ou de redes econômicas - como a OTAN, a OCDE ou a assim tríade - constroem-se para além dos Estados nacionais outras fronteiras que adquirem um significado tão grande para os interesses nacionais como as fronteiras do próprio território ${ }^{287}$.

\footnotetext{
${ }^{286}$ HABERMAS, Jürgen. A constelação pós-nacional: ensaios políticos. Tradução de Márcio Seligmann-Silva. São Paulo: Littera Mundi, 2001, p. 88.

${ }^{287}$ HABERMAS, 2001. Op. cit., p. 90.
} 
A partir da constatação de que existem fronteiras além daquelas geográficas, como afirma Habermas, foram constituídos organismos internacionais capazes de resolver, até mesmo com a imposição de sanções, questões entre nações e internas dos Estados, principalmente no que se refere à violação de direitos humanos.

Nestes moldes tornou-se necessária a imposição de obrigações e, posterior apuração de responsabilidades bem como a instituição de mecanismos sancionadores para aqueles Estados que transgridam os compromissos assumidos perante o Direito Internacional.

Conforme Cretella Neto "a responsabilidade internacional é um princípio do Direito Internacional, e também conceito geral de Direito, o de que toda violação de um compromisso implica na obrigação geral de reparar ${ }^{288 "}$.

A tais organizações internacionais, como é o caso da OMC (Organização Mundial do Comércio), é dada a função de julgar e, se for o caso, condenar os Estados por violação a tratados e demais normas internacionais, consagrandose, pois, o princípio da responsabilidade internacional.

Nos dizeres de Antônio Celso Alves Pereira:

[...] (as organizações) são realidades dinâmicas da sociedade internacional que se estruturou pós-45, representando hoje o marco mais importante e efetivo para a democratização do Direito Internacional clássico, Fator de estabilização do sistema internacional, essas organizações promovem a expansão geográfica do Direito Internacional, contribuindo dessa forma para sua universalização ${ }^{289}$.

Em virtude da apuração e posterior eventual condenação por transgressão ambiental a nível internacional, isto é, a concretização do princípio da responsabilidade internacional, é que se faz necessária a abordagem da questão de internacionalização do direito ambiental com a consequente criação de organismos ambientais globais. Certo é que aplicação do princípio em comento no direito internacional ambiental ainda carece de efetivação.

\subsection{A internacionalização do Direito Ambiental: PNUMA e OMMA}

O direito ao meio ambiente ecologicamente equilibrado é considerado direito fundamental de terceira geração, alicerçado na solidariedade entre gerações e entre a mesma geração.

\footnotetext{
${ }^{288}$ CRETELLA NETO, José. Da responsabilidade internacional das organizações internacionais. In: DIREITO, Carlos Augusto Menezes; PEREIRA, Antônio Celso Alves; TRINDADE, Antônio Augusto Cançado (Orgs.). Novas perspectivas do direito internacional contemporâneo: estudos em homenagem ao professor Celso D. de Albuquerque Mello. Rio de Janeiro: Renovar, 2008. pp. 135-137. ${ }^{289}$ PEREIRA, Antônio Celso Alves apud CRETELLA NETO, José. Op. cit., 2008. pp.135-.145.
} 
É principalmente baseado nesta solidariedade entre a presente geração que se desenvolveu a internacionalização do direito ambiental, uma vez que os danos ao meio ambiente desconhecem fronteiras. $\mathrm{O}$ desastre ambiental, muitas vezes, ocorre em um território específico e gera consequências - ambientais, econômicas e sociais - em outros locais, como no caso das poluições transfronteiriças e da mudança climática.

Os efeitos danosos da opção de um país por uma matriz energética "suja", como o petróleo, atingem outras nações que, por sua vez, podem ter como escolha uma matriz de energia limpa. Ou seja, mesma optando por não contribuir para o desastre ambiental, denominado aceleração da mudança climática, um Estado sofre as consequências das escolhas erradas de outros.

"A mudança de clima é mais difusa ao causar efeitos diretos a terceiros Estados que não aos próprios emissores" ${ }^{\prime 290}$, uma vez que a atmosfera que recebe os gases de efeito estufa é única, circundando todo a Terra.

Desta forma, claro está que a preocupação ambiental deve ser internacional, não se aplicando somente no âmbito interno dos países. Conforme José Adércio Leite Sampaio: "Uma outra manifestação de comunialidade no Direito Internacional do Meio Ambiente pode ser vislumbrada na noção de que determinadas questões ambientais constituem preocupação comum da humanidade ${ }^{291}$."

Nesta esteira, se inicia a partir da Conferência das Nações Unidas sobre o Meio Ambiente Humano, realizada em Estolcomo em 1972, a tentativa de consolidação e sistematização das normas ambientais no plano internacional, uma vez que o conteúdo normativo ambiental se restringia, na maioria das vezes, ao âmbito interno nacional e ocorreria de maneira dispersa.

A preocupação jurídica pelos problemas ambientais assume caráter mundial. "Por essa razão, houve um aumento significativo do número de instrumentos de proteção ambiental que deixaram de lado a preocupação exclusiva com as regras internas e regionais ${ }^{292}$. Fato que levou a Organização

\footnotetext{
${ }^{290}$ SANTOS, Abraão Soares dos; SANTOS, Maria Angélica dos Santos. A proteção jurídica da sociobiodiversidade em face do novo conceito de soberania e do princípio do consentimento. In: XV Congresso Nacional do CONPEDI, 2007, Manaus, p. 1. Disponível em: http://www.conpedi. org.br/manaus/arquivos/anais/manaus/direito_ambiental_abraao_dos_santos_e_maria_dos_ santos.pdf. Acessado em: 05.05.2012.

${ }^{291}$ SAMPAIO, José Adércio Leite. Constituição e meio ambiente na perspectiva do direito internacional comparado. In: NARDY, Afrânio; SAMPAIO, José Adércio Leite; WOLD, Chris. Princípios de direito ambiental: na dimensão internacional e comparada. Belo Horizonte: Del Rey, 2003. pp. 37-116, p. 13.

${ }^{292}$ OLIVEIRA, Rafael Santos de. Comércio Internacional e proteção do meio ambiente: um diálogo possível?. In: OLIVEIRA, Rafael Santos de Oliveira; PES, João Hélio Ferreira (Coords.). Direito ambiental contemporâneo: prevenção e precaução. Curitiba: Juruá, 2009. pp. 239-260, p. 239.
} 
das Nações Unidas a criar em 1972 o PNUMA, cujo o principal objetivo é promover mecanismos de conservação do meio ambiente em uma diretriz que leve ao uso dos recursos naturais de maneira sustentável.

No entanto, quarenta anos após sua criação, o PNUMA mostra-se incapaz de solucionar a atual crise ambiental. Tal fato se deve, principalmente, em virtude da pouca força vinculativa que o organismo internacional em questão detém, justamente por ter sido constituído como um programa e não nos moldes da OMC.

Centenas de documentos internacionais foram estabelecidos após a criação do PNUMA, no entanto, a grande maioria não tem efetividade na ordem internacional. O Protocolo de Kioto, acordado durante a COP 3 em 1997, tornou-se o mais claro exemplo de ineficácia da organização em debate, uma vez que os países que não cumpriram o estabelecido no pacto não sofrerem nenhum tipo de sanção internacional.

Torna-se, pois, necessária a criação de uma organização internacional com boa infraestrutura, dotação orçamentária própria, autonomia e poderes para impor sanções aos países que descumprirem pactos ambientais firmados a nível mundial. Para muitos tal organização seria a OMMA (Organização Mundial do Meio Ambiente).

O fortalecimento do PNUMA, isto é, a criação de um organismo internacional ambiental com força sancionadora, no caso a OMMA, vem como concretização de uma ingerência ambiental a nível global, em virtude do acatamento da seguinte questão: o controle ambiental deve ser feito mundialmente, uma vez que a natureza desconhece os limites políticosgeográficos impostos pelo ser humano.

A OMMA deve ser instituída nos moldes da OMC, a qual possui no seu interior um Órgão de Solução de Controvérsias (OSC), não sofrendo dos mesmos vícios de outras organizações que assim como o PNUMA "tem como elemento de fragilidade a dependência do voluntarismo dos Estados ${ }^{293}$ ", como é o caso da Organização Internacional do Trabalho (OIT) e da Organização Mundial de Saúde (OMS).

A implementação de uma organização internacional que tenha o poder de sancionar os Estados sujeitaria as partes dos acordos internacionais ambientais às responsabilidades inerentes a manifestação de vontade. $\mathrm{O}$ fato faria com que os documentos internacionais ambientais, ao certo, vinculassem as nações no comprometimento com o meio ambiente, seja por "medo" da sanção ou por respeito à natureza. $\mathrm{O}$ certo é que a ineficácia desses documentos leva à insegurança jurídica e gera descrença popular na busca de soluções ambientais através do Direito.

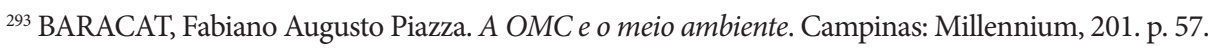


O Direito Internacional Ambiental não pode ter puramente um caráter simbólico, de representação abstrata de uma vontade. Deve ser constituído sob os moldes de concretização desta que se funda no fato de querer manter o meio ambiente como um local onde se encontre vida humana e as outras espécies de vida num padrão mínimo de qualidade, isto é, respeitados os padrões estabelecidos a partir de um mínimo existencial ecológico. Não é possível que a vontade se situe somente no plano da ficção, no qual os Estados não tenham metas e posteriores sanções concretas para com o meio ambiente ecologicamente equilibrado.

Nos dizeres de François Ost, a atitude dos Estados de não transporem para o plano interno as normas internacionais ambientais é considerada uma "esquizofrenia estatal ${ }^{294 "}$. O jurista complementa ao afirmar que:

[...] a distância entre as intenções fixadas nos textos e a realidade da sua aplicação no terreno não é suprimida. Este fenômeno verifica-se, muito particularmente, nos tratados internacionais: mal os Estados subscrevem novos compromissos no final de uma conferência altamente mediatizada, logo se apressam a voltar ao seu comportamento anterior ${ }^{295}$.

No entanto, a partir do momento em que se cria uma organização internacional ambiental com força sancionadora os Estados ficam compelidos em internalizar os documentos internacionais pactuados, de forma a surgir uma ingerência internacional no território estatal, a qual não ocorre de forma tranquila, existindo muito descontentamento, a nível mundial, dessa forma de mitigação ${ }^{296}$ da soberania nacional.

\section{SObERANIA NACIONAL: INGERÊNCIA INTERNACIONAL NO TERRITÓRIO NACIONAL}

A soberania nacional, que no plano externo implica na autonomia de um Estado frente aos demais, é uma das bases dos Estados modernos, de tal modo que qualquer modificação no seu significado enseja profundas considerações.

O estudo acerca da soberania estatal deve passar anteriormente pelo enfretamento do tema relativo ao princípio da não intervenção que rege o Direito Internacional.

A partir da Declaração sobre princípios do Direito Internacional referentes as relações de amizades e cooperação entre os Estados, restou evidente o

\footnotetext{
${ }^{294}$ OST, François. A natureza à margem da lei: a ecologia à prova do direito. Tradução de Joana Chaves. Lisboa: Instituto Piaget, 1995, p. 130.

${ }^{295}$ OST, 1995. Op. cit., p. 130.

${ }^{296}$ A palavra mitigação será usada neste artigo como sinônimo de reconstrução, reformulação.
} 
compromisso internacional assumido em se preservar a soberania estatal e reconhecê-la como princípio.

Neste sentido, criou-se a nível mundial o princípio da não intervenção ou não ingerência, pelo qual a comunidade internacional bem como cada nação devem se abster de interferir na ordem interna de um Estado soberano.

Guerra adverte que:

No âmbito das Nações Unidas, o artigo $2^{\circ}$, alínea 1 da Carta da ONU estabelece que a Organização é baseada no principio da igualdade soberana de todos os seus membros, bem como, na alínea 7 do mesmo artigo, que nenhum dispositivo da presente Carta autorizará as Nações Unidas a intervirem em assuntos que dependam essencialmente da jurisdição interna de qualquer Estado ou obrigará os membros a submeterem tais assuntos a uma solução $[\ldots]^{297}$.

No entanto, a aplicação do princípio da não intervenção, originada da ideia de soberania estatal, não pode constituir óbice para a efetivação da proteção do direito humano ao meio ambiente ecologicamente equilibrado, como estipulado no caput do artigo 225 da Constituição da República Federativa do Brasil e em diversos documentos internacionais.

Neste sentido Habermas adverte:

Anecessidade de ingerência torna-se evidente ao se discutir questões como biodiversidade, seja ela aquática ou terrestre. Animais, originalmente pertencentes a zonas aquáticas ou a biomas específicos não ocupam ou se reproduzem nos limites/fronteiras de seus territórios, fato que eleva a proteção ambiental a um nível extra-local ou "supranacional ${ }^{298 "}$.

Em matéria ambiental, uma vez que as questões ambientais estão intrinsecamente ligadas à vida, torna-se necessário uma reconstrução do significado de soberania nacional, a fim de se evitar o agravamento da crise ecológica que vivemos.

Ressalte-se que não é defensável a tese de mitigação também da soberania sobre os recursos naturais, a qual difere da soberania nacional, uma vez que "os

\footnotetext{
${ }^{297}$ GUERRA, Sidney. O direito de ingerência em matéria ambiental. In: DIREITO, Carlos Augusto Menezes; PEREIRA, Antônio Celso Alves; TRINDADE, Antônio Augusto Cançado (Orgs.). Novas perspectivas do direito internacional contemporâneo: estudos em homenagem ao professor Celso D. de Albuquerque Mello. Rio de Janeiro: Renovar, 2008. pp.255-271, p. 263.

${ }^{298}$ HABERMAS, 2001. Op. cit.
} 
Estados têm o direito soberano de explorar seus recursos naturais de acordo com suas próprias políticas nacionais ${ }^{299}$ ". Não há que se confundir estas duas formas de soberania, uma vez que discute-se neste artigo somente a reconstrução da soberania nacional.

No entanto, a partir do momento em que a exploração de recursos naturais, e não a titularidade sobre eles, se dê em desconformidade com as normas internacionais assumidas pelos países espontaneamente, através do princípio do consentimento que rege o Direito Internacional, torna-se necessária a interferência de órgãos externos na atividade ecológica interna dos países. Isto é, o controle internacional não se dará diretamente sobre os recursos naturais do Estado soberano, mas sim sobre a degradação que a utilização desses recursos pode provocar em âmbito global. Tal fato enseja a perda de parcela da soberania nacional, até então absoluta nas questões ambientais.

Atente-se que a ingerência internacional em Estados soberanos deve atender a critérios de harmonização entre o individualismo de cada nação, isto é, suas peculiaridades, e a consciência de que todos vivem num único espaço - a Terra.

Habermas enfrenta o tema na seguinte passagem:

A institucionalização de procedimentos para a sintonização mundial dos interesses, para a universalização dos interesses e para construção criativa de interesses comuns não poderá se consumar na figura organizadora de um Estado mundial (tampouco desejável); esse processo terá de levar em conta a independência [Eigenstädigkeit], os caprichos [Eigenwilligkeit] e a peculiaridade [Eigenart] dos Estados outrora soberanos ${ }^{300}$.

A fim de que sejam encontradas as melhores e mais eficazes soluções para os problemas ambientais, os juristas propõem a desmistificação de antigos dogmas no que se refere à teoria do estado, como pode se obervar a partir da passagem da soberania nacional para uma soberania compartilhada.

\subsection{A RECONSTRUÇÃo da SObERANiA NACIONAL}

Passada a fase dos breves questionamentos acerca da responsabilidade estatal em relação ao meio ambiente, cumpre esclarecer como a efetivação daquela levará, consequentemente a reconstrução do conceito clássico de soberania nacional, no qual esta é caracterizada como absoluta. Isto é, a necessidade de "ecologização do direito ${ }^{301}$ " internacional torna razoável que se defenda a bandeira da supranacionalidade em matéria ambiental.

\footnotetext{
${ }^{299}$ SAMPAIO, 2003. Op. cit. pp. 37-116, p.10.

${ }^{300}$ HABERMAS, 2001. Op. cit. p. 74.

${ }^{301}$ OST, 1995 . Op. cit. p. 118.
} 
Beck $^{302}$, assim como Habermas ${ }^{303}$, apontam como uma das soluções para a crise global, no que tange principalmente a efetivação de direitos humanos, a aceitação em nível mundial da supranacionalidade, isto é, o a remodelação da soberania para além das nações.

Em virtude da universalidade das ameaças as soluções também devem se dar de maneira global. Pode-se citar a título de exemplo a poluição atmosférica e hídrica, as quais desconhecem os limites territoriais de um Estado soberano, o que torna evidente o fato de utilizarmos uma divisão política e geográfica que não poderia servir de obstáculos para a proteção ambiental, uma vez que o planeta se comporta como um organismo vivo integrado ${ }^{304}$.

Conforme Beck:

No centro da questão estão os riscos e efeitos da modernização, que se precipitam sob a forma de ameaças à vida de plantas, animais e seres humanos. Eles já não podem - como os riscos fabris e profissionais no século XIX e na primeira metade do século XX - ser limitados geograficamente ou em função de grupos específicos ${ }^{305}$.

A partir desta constatação, baseados nos ensinamentos de Jean Bodin, Santos e Santos propõem um aprofundamento no debate acerca da "releitura constitucional do conceito de soberania ${ }^{306 "}$ baseada no princípio do consentimento que abarca o Direito Internacional.

O Direito Internacional Ambiental, a partir de uma interpretação conforme a Constituição brasileira, deve ser capaz de "alcançar a normatividade para além do estado nacional, em especial, verifica-se que o princípio do consentimento como fonte do Direito Internacional ganha novos contornos diante da mudança do conceito de soberania ${ }^{307 "}$.

Os problemas ambientais são mundiais, de tal forma que as soluções também devem ser tomadas a nível global, isto é, a responsabilidade ambiental é de cada um dos Estados que compõem o globo terrestre, ao mesmo tempo em que é conjunta destas mesmas nações.

Graças à quebra do equilíbrio ecológico e à capacidade de destruição embutida na aplicação da técnica de ponta surgiram, no entanto, novos riscos

\footnotetext{
${ }^{302}$ BECK, Ulrich. Sociedade de risco: rumo a uma outra modernidade. Tradução de Sebastião Nascimento. São Paulo, 2010. p. 16.

${ }^{303}$ HABERMAS, 2001. Op. cit.

${ }^{304}$ Teoria de Gaia, formulada por J. Lovelock, na qual a Terra é definida como um ser vivo a procura do seu equilíbrio homeostático.

${ }^{305}$ BECK, 2010. Op. cit. p. 16.

${ }^{306}$ SANTOS e SANTOS, 2006. Op. cit. p. 1.

${ }^{307}$ SANTOS e SANTOS, 2006. Op. cit. p. 3.
} 
que ultrapassam as fronteiras. "Chernobyl", "buraco de ozônio" ou "chuva ácida" indicam acidentes e modificações ecológicas que, por causa das suas amplas consequências e intensidades, não se deixam mais controlar nos âmbitos nacionais e que, consequentemente, ultrapassam a capacidade de ordenação dos Estados singulares ${ }^{308}$.

A responsabilidade ambiental assume caráter internacional. Não pode, pois, ser atribuída somente aos Estados individualmente. Isto é, todos são responsáveis pelo todo. Para que esta responsabilidade se concretize é necessário que se imponha um novo significado à soberania estatal.

Nos ensinamentos de Cretella Neto:

Se a responsabilidade pelo futuro comum do planeta é de todas as nações, a concepção clássica de soberania estatal no que tange ao direito ambiental parece ruir. A responsabilidade compartilhada por todos os habitantes do planeta "impõe-se como corolário do princípio da igualdade entre estes $[\ldots]^{309 "}$.

Hodiernamente, a soberania nacional sob a forma clássica em que se constitui encontra-se em uma nítida crise de existência, principalmente no que se refere aos danos ambientais. "Esse é o fim do século XIX, o fim da sociedade

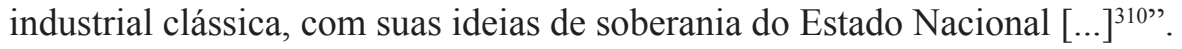

Beck salienta que há uma "socialização do danos à natureza" derivada do modo de vida da sociedade de consumo atual. Para o filósofo:

O reverso da natureza socializada é a socialização dos danos à natureza, sua transformação em ameaças sociais, econômicas e políticas sistêmicas da sociedade mundial altamente industrializada. Na globalidade da contaminação e nas cadeias mundiais de alimentos e produtos, as ameaças à vida na cultura industrial passam por metamorfoses sociais de perigo: regras da vida cotidiana são viradas de cabeça para baixo ${ }^{311}$.

Não há que se utilizar institutos do passado para regular a vida de uma humanidade que se modificou, até porque as crises ecológicas e sociais também foram alteradas. A busca por institutos mais adequados para os novos problemas passa pela criação de uma organização internacional ambiental que regule a relação ambiental global.

\footnotetext{
${ }^{308}$ HABERMAS, 2001. Op. cit. p. 87.

${ }^{309}$ CRETELLA NETO, 2008. Op. cit. pp.135-178, p. 136.

${ }^{310}$ BECK, 2010. Op. cit. p. 10.

${ }^{311}$ BECK, 2010. Op. cit., p. 10.
} 
O cenário mundial foi alterado e a forma como a soberania nacional se desenvolve não pode restar inatingível. A participação em Organismo Internacional pressupõe perda da soberania tradicional, mas manutenção da soberania compartilhada. O que é, de fato, característica dos governos nos século XX e XXI, nos quais temos uma "soberania fluida" ${ }^{312}$ ".

\section{O PRINCÍPIO DO PATRIMÔNIO COMUM DA HUMANIDADE}

A elaboração de princípios jurídicos como tentativa de concretização da proteção ambiental encontra-se firmemente presente na agenda internacional contemporânea em conjunto com proteção dos direitos humanos, os temas acerca do desenvolvimento dos povos e do desarmamento.

O Direito Internacional Ambiental surge como um dos meios de regulação do meio ambiente mundial, principalmente devido à intrínseca relação entre efetivação dos direitos humanos e proteção ambiental.

Neste contexto, em que acende no cenário internacional o instituto da soberania compartilhada, é que se fazem presentes e, necessários, os debates acerca do princípio do patrimônio comum da humanidade juntamente com o postulado da solidariedade, uma vez que estes fundamentam a ideia de soberania compartilhada.

O princípio do patrimônio comum da humanidade nas lições de Leite Sampaio "constituiu uma limitação e se contrapõe ao princípio da soberania permanente sobre os recursos naturais. Ele afirma, fundamentalmente, que determinados recursos são comuns a toda a humanidade ${ }^{313}$ ".

O jurista argumenta ainda que:

"O conceito de patrimônio comum da humanidade foi construído, assim, como uma forma de se afirmar que nenhum Estado poderia reivindicar a propriedade dos recursos em consideração, o que, entretanto, não impedia a sua exploração de acordo com regras voltadas para assegurar o compartilhamento pela comunidade internacional dos benefícios obtidos ${ }^{314}$ ".

Percebe-se claramente que o princípio em tela desfigura o conceito clássico de soberania nacional ao determinar que alguns recursos naturais são comuns a todas as nações, portanto nenhuma teria autonomia sobre aqueles. $\mathrm{O}$ uso soberano dos recursos naturais pelos Estados é colocado em xeque, fato que enseja tormentosas discussões.

\footnotetext{
${ }^{312}$ HABERMAS, 2001. Op. cit.

${ }^{313}$ SAMPAIO, 2003. Op. cit., p. 37-116, p.12.

${ }^{314}$ SAMPAIO, 2003. Op. cit., p. 37-116, p.13.
} 
De um lado a soberania sobre os recursos naturais encontra-se consagrada em diversos documentos internacionais como a Declaração sobre a concessão de Independência aos Países e Povos Coloniais ${ }^{315}$ e na Resolução da ONU sobre Soberania Permanente sobre os Recursos Naturais ${ }^{316}$. É defendida, principalmente, pelos países subdesenvolvidos e em desenvolvimento, os quais reivindicam o uso soberano de seus recursos naturais como forma de crescimento econômico.

Noutro sentido tem-se o princípio do patrimônio comum da humanidade alicerçado no ideal de solidariedade e, que resulta em uma consequente mitigação da soberania. Esta vertente encontra fundamentos crescentes na comunidade jurídica internacional, baseada, principalmente, no surgimento de problemas ambientais alçados a nível planetário como a mudança do clima terrestre e a poluição das águas doces e salgadas.

Conforme Carvalho:

Não quer dizer aqui que tal elaboração conceitual de patrimônio da humanidade seja expandida para ser aplicada a todos os recursos, mas que se deve buscar o equilíbrio apropriado para um novo mundo interdependente, orientado pela solidariedade mundial e organizado em bases equitativas e racionais ${ }^{317}$.

Uma vez aceita a noção de existência de um patrimônio que não pode ser individualizado, isto é, um bem pertencente a toda a humanidade, há que se definir como os indivíduos se situam no debate.

Habermas ao se referir ao fortalecimento dos direitos humanos e da democracia sustenta que a relação entre os Estados se estende para além dos limites geográficos nacionais, fato que faz surgir um sentimento individual de "co-pertença a partir de uma rede de interesses comuns existentes ${ }^{318 "}$.

A situação descrita pelo filósofo se aplica perfeitamente à questão ambiental, de tal maneira que a ideia de co-pertença justifica a consagração do princípio da solidariedade como base do Direito internacional Ambiental uma vez que o interesse comum a que Habermas se refere pode ser representado pela vontade que as nações demonstram de continuidade de existência dos homens.

A ideia de interesse comum, de fato, passa pela manutenção da segurança ecológica, não sendo esta possível sem que os Estados compreendam a

\footnotetext{
315 CARVALHO, Edson Ferreira. Meio ambiente como patrimônio comum da humanidade: princípios fundamentais. Curitiba: Juruá, 2008. p. 85.

316 CARVALHO, 2008. Op. cit., p.85.

${ }^{317}$ CARVALHO, 2008. Op. cit., p.68.

${ }^{318}$ HABERMAS, 2001. Op. cit., p.27.
} 
interdependência em matéria ambiental e a consequente soberania compartilhada, a qual se daria pelo surgimento de uma maior ingerência internacional ambiental representada pela criação da OMMA.

A busca pela proteção do patrimônio comum, alicerçada pela solidariedade, e o interesse em continuidade de existência que move os Estados é o fator que impõe a estes a proteção e respeito pela base jurídica internacional que estipule obrigações ambientais, podendo, até mesmo limitar direitos/ liberdades já existentes, como é a soberania nacional.

Por fim, "fica evidente que não existem "eles" e "nós, mas somente "nós" que, mesmo não possuindo uma origem em comum, temos, certamente um destino comum a ser discutido a cada dia que acordamos ${ }^{319}$ ". A reconstrução do conceito de soberania nacional passa pelo fundamento de que os problemas ambientais não podem ser solucionados de forma fragmentada tendo em vista a existência do interesse em comum que mobiliza a ordem mundial: a existência do homem na Terra.

\section{Conclusão}

Certamente, as organizações internacionais sancionadores, como é a OMC e como será a OMMA, não são capazes, sozinhas, de reverter o quadro problemático na relação do homem com a natureza. Torna-se necessária a atuação conjunta dos diversos setores - sistema educacional, biologia, antropologia, filosofia, economia, física, química, entre outros - para desempenharem tal papel salvador.

Importante frisar que os atores sociais são muitos e incontáveis. Pode ser atribuído este papel em conjunto tanto aos governos dos países, a uma governança mundial bem como a uma pequena organização social não governamental que se forme em determinada comunidade. No entanto, atitudes isoladas de países não resolverão por si só a crise ambiental que vivemos, torna-se imprescindível que num mundo globalizado economicamente e ambientalmente, já que as fronteiras ecológicas são inexistentes, se busque instrumentos capazes de efetivar - através do elemento da vinculação num primeiro momento - os compromissos assumidos pelas nações em âmbito internacional.

Para que o elemento vinculativo seja cumprido, muitas vezes os organismos internacionais deverão interferir nas decisões dos Estados, relativizando, neste momento a soberania nacional. No entanto, esta mesma soberania, que agora pode ser tida como compartilhada, já foi mitigada quando a nação confirmou sua adoção ao princípio do consentimento em âmbito internacional, isto é, quando por livre vontade assumiu compromissos ambientais internacionalmente.

${ }^{319}$ SANTOS e SANTOS, 2006. Op. cit., p.11. 
Por fim, a inevitável flexibilização da soberania nacional, uma vez que a governança ambiental a nível global através da OMMA se faz necessária, nada mais é que uma reconstrução do conceito de soberania estatal de modo a adequá-la às necessidades de harmonização do homem com a natureza na busca pela concretização do princípio da solidariedade respaldada no interesse comum da humanidade, que é o de manutenção da vida no Planeta Terra. 


\section{REFERÊNCIAS}

BARACAT, Fabiano Augusto Piazza. A OMC e o meio ambiente. Campinas: Millennium, 2012.

BECK, Ulrich. Sociedade de risco: rumo a uma outra modernidade. Tradução de Sebastião Nascimento. São Paulo, 2010.

CARVALHO, Edson Ferreira de. Meio ambiente como patrimônio da humanidade: princípios fundamentais. Curitiba: Juruá, 2008.

GUERRA, Sidney. O direito de ingerência em matéria ambiental. In: DIREITO, Carlos Augusto Menezes; PEREIRA, Antônio Celso Alves; TRINDADE, Antônio Augusto Cançado (Orgs.). Novas perspectivas do direito internacional contemporâneo: estudos em homenagem ao professor Celso D. de Albuquerque Mello. Rio de Janeiro: Renovar, 2008.

HABERMAS, Jürgen. A constelação pós-nacional: ensaios políticos. Tradução Márcio Seligmann-Silva. São Paulo: Littera Mundi, 2001.

NETO, José Cretela. Da responsabilidade internacional das organizações internacionais. In: DIREITO, Carlos Augusto Menezes; PEREIRA, Antônio Celso Alves; TRINDADE, Antônio Augusto Cançado (Orgs.). Novas perspectivas do direito internacional contemporâneo: estudos em homenagem ao professor Celso D. de Albuquerque Mello. Rio de Janeiro: Renovar, 2008.

OLIVEIRA, Rafael Santos de. Comércio Internacional e proteção do meio ambiente: um diálogo possível? In: OLIVEIRA, Rafael Santos de Oliveira; PES, João Hélio Ferreira (Coords.). Direito ambiental contemporâneo: prevenção e precaução. Curitiba: Juruá, 2009.

OST, François. A natureza à margem da lei: a ecologia à prova do direito. Tradução de Joana Chaves. Lisboa: Instituto Piaget, 1995.

SAMPAIO, José Adércio Leite. Constituição e meio ambiente na perspectiva do direito internacional comparado. In: NARDY, Afrânio; SAMPAIO, José Adércio Leite; WOLD, Chris. Princípios de direito ambiental: na dimensão internacional e comparada. Belo Horizonte: Del Rey, 2003.

SANTOS, Abraão Soares dos; SANTOS, Maria Angélica dos Santos. A proteção jurídica da sociobiodiversidade em face do novo conceito de soberania 
e do princípio do consentimento. In: XV Congresso Nacional do CONPEDI, 2007, Manaus, p.1. Disponível em: http://www.conpedi.org.br/manaus/arquivos/anais/manaus/direito_ambiental_abraao_dos_santos_e_maria_dos_santos. pdf. Acessado em: 05.05.2012.

SILVA, Alice Rocha. Direito internacional público e soberania na Constituição brasileira: aplicação de decisões do órgão de solução de controvérsias da Organização Mundial do Comércio (OMC) no ordenamento jurídico brasileiro. In: Revista Jurídica, Brasília, v. 8, n. 80, ago./set., 2006. 